introduction of the tenotome beneath the skin. The forceps being dispensed with, the finger and thumb of the left hand firmly grip the sternal portion of the muscle and lift it away from the deep structures of the neck. The tenotome is then slid transversely behind the tendon from the inner side, and a moderate degree of tension put upon it by traction on the head by the chief assistant, a similar amount of traction being applied at the same time to the upper limb on the affected side. The tendon is thus cut through slowly and the tenotome withdrawn. The surgeon then kneads the muscle, especially the clavicular portion, whilst the chief assistant stretches the contracted tissues by rotation and extension of the head. A dressing is now applied, followed by a plaster-ofParis jacket, with the head in the over-corrected position, and the shoulder on the affected side pulled well down. The application of the plaster cast is much facilitated if the operation be performed on the orthopaedic operation table described at page 721 of this issue, which was inrented some rears ago, and shown at the Orthopacdic Section of the Royal Society of Medicine on February 7th, 1928. If this be not arailible, then the plaster should be applied with the patient lying on a simple pelvic rest. The points to be enphasized in its application are pressurc beneath the chin, mastoid process, and shoulder on the affected side, and adequate airway.

The plaster jacket is not as irksome as might appear patients being able to walk, and even play football and ride a donkey. This is bi-valved in four weeks' time, and exercises and re-education are commenced by the masseuse. At first the exercises should be carried out in the prone position, with the head low to avoid the faintness sonetimes experienced on removal of the jacket. It is worn as a corrective splint for another four weeks, and then it is discarded. A complete cure usually results in three to six months, depending on the degree of deformity present per se, as well as the secondary ones; naturally the facial asymmetry takes longest to disippicar.

It should be emphasized that the masseuse undertaking the treatment should make the acquaintance of the patient some dars before the operation in order to initiate the corrective exercises which will be necessary afterwards, and should, of course, be present at the operation.

\section{Results of Operation.}

The resilts of operation by this method were complete cures in 19 out of 20 cases; the one case which was a partial success was made a complete one by open division of the attachment at the mastoid process.

The risks of the closed operation are not great provided the tendon is carefully lifted from the deeper structures of the neck and the surgeon has adequate skilled assistance. All the instruments necessary for the open division of the tendon are, of course, readily sterilized for use should anything unforeseen arise. The resulting fine pinprick scar is of great cosmetic importance to a girl.

Indications for Open Operation.

The indications for open operation are: (1) incomplete cure or relapse from the subcutaneous method; (2) cases in which there are other abnormalities-for example, Sprengel's shoulder, or congenital cervical scoliosis, ats shown by the presence of wedged vertebrae, etc. In such cases the deeper structures are contracted, and will require stretching or even division.

The incision is preferably obliquely transverse over the sternal end of the clavicle to make the scar as inconspicuous as possible, the platrsma is divided, and then the sternal head of the muscle over an elcrator. The clavicular head seldom gives trouble, exccit in those instances where a previous operation may have caused fibrous tissue formation. The head is then stretched to the over-corrected position, the soft tissues carefully sewn up with fine catgut, and the skin with fine salmon gut, and a plaster jacket applied. The resulting scar is disfiguring, and tends to broaden as years go by.

Contraindications for Operation.

1. Those cases in which $x$-ray films show a marked congenital bony deformity, generally due to wedged vertebrae, with perhaps cervical ribs.
2. Bilateral torticollis I have seen three such cases.

3. Those cases in which the torticollis is secondary to clisease of the spine-for example, tubercle.

In all the above, where bony deformity is present, it would be of little value to divide the contracted soft structures, as the bony ones would remain, and these are not correctable.

Summary.

This paper has been written, and these photographs of cases before, during, and after treatment have been shown, in order to emphasize that torticollis may be prevented hy careful ante-natal examination of the mother to secure the simplest presentation, avoiding natal injury. Further, the younger the infant the sooner the cure. Lastly, the subcutaneous tenotomy of the sterno-mastoid muscle gives a complete, lasting, scarless result.

\section{CONGENITAL POLYCYSTIC DISEASE OF 'I HE KIDNEYS AND LIVER.}

\author{
BY
}

GRAHAM C. CAMPBELL, M.R.C.S., L.R.C.P.,

LATE RESIDENT MEDICAL OFFICER, ROYAL UNITED HOSPITAL, BATH.

THE following case of - congenital polycystic disease of the kidneys and liver is interesting not only on account of the pathological condition of the liver, but also because of the family history. As happens in so many similar cases, the condition of the kidneys and liver was only discovered at post-mortem examination: during the lifetime of the patient it had never been considered in the differential diagnosis of his illness.

History.

A. H., a male aged 55, saw his family doctor in February, 1929 He had been sent by his wife because of occasional vomiting, fron which he had suffered during the preceding fortnight. His own mental outlook was curious, in that he seemed quite unconscions of the fact that he was ill. At that time he was very anacmic: his tongue was pale and flabby, but there was no glossitis. liv liver was slightly palpable in the right hypochondrium. The illness was was slighty palpable in the right hypochondrium. The illess was diagnosed as Addison's anaemia, and he was ordered to rest Following the adoption of this treatment, especially after taking the liver, he vomited several times, and the administration o liver was therefore stopped. Two days later he had a copious bright red hasmorrhage from the rectum; rectal examination revealed no abnormality. He was given kalzana tablets and an intramuscular injection of $4 \mathrm{c.cm}$. of thromboplastin, but this anc subsequent injections of the same drug had no effect. Following the second injection he had hacmorrhage from the right nosiril, which was successfully plugged with gauze soaked in adrenaline. which was successfully plugged with gauze soaked in adrenaline. The next day blecding occurred from a small denuded area in the situation of the lower left canine tooth; this was finally arrested
by a turpentine application. A blood count made at this time showed marked diminution in the number of red cells $2,500,000$ per c.mm.), but no obvious change in the white count. The urine was pale in colour; its specific gravity was 1010; it contained no sugar, but traces of albumin and an occasional cast were found. The optic discs though pale were normal, and no retinal haemorrhages were seen.

'The patient now began to be rather sleepless, and there was marked tremor of the fingers. The bleeding from the rectum persisted, and to check it he was given by mouth an emulsion of half an ounce of turpentine with half an ounce of castor oil. Following this treatment haemorrhage stopped for one day, but it reappeared on the next day. Neither suppression of urinc nor hacmaturia followed the administration of turpentine.

He was admitted to hospital on February 16 th, about a fortnight after his first visit to his private doctor. He complained of a dull ache in the right loin, and preferred to lie on his left side. In hospital he was given an intravenous injection of calcium chloride, without, however, any apparent effect on the hacmorrhage. He died on February 18th.

\section{Post-mortcm Findings.}

Kidncys.-Both kidneys were equally enlarged and cyslic; each weighed $2 \mathrm{lb}$. and measured $6 \frac{7}{3}$ inches from its upper to lower pole and $3 \frac{3}{4}$ inches in breadth. The cysts varied in size from that of a pea to that of a walnut.

Livcr.-The liver was uniformly enlarged, and wcighed $3 \frac{1}{2} \mathrm{lb}$. Its anterior surface measured $6 \frac{3}{8}$ inches by $6^{3}$ inches by $7 \frac{3}{4}$ inches. Its anterior surface measured 18 ince was thickly studded with small cysts, the size Its whole substance was thickly studded with
of which varied up to that of a hazel nut.

Other Organs.-No cysts were seen in the pancreas, and no pathological condition was found in any other organ.

Microscopical Examination.

The scetion of liver examined microscopically showed typical congenital cysts. Normal liver tissue was seen, between which were spaces lined with a flattened epithelium. The normal tissue was not compressed, and the cysts probably arose from ordinary was not compressed, and the cysts probably arose
liver-forming cells very early in their development. 


\section{Family History.}

The patient was the youngest of ten children, one of whom dicd at birth; of the rest, only one is alive, a woman aged 69 , apparently in good health. His mother died from Bright's known) when 85. The following is a list of the children in order: (1) a male, died at the age of 1 ycar from convulsions; (2) a (1) a male, died at the age of 1 ycar from convulsions; (2) a
female, aged 69 , still alive: (3) a female, died from convulsions, aged $2 ;$; (4) a female, died at the age of 49 , and post-mortem examination revealed cystic kidneys; (5) a female, died of kidney trouble, aged 45; (6) a male, died from convulsions, aged 2; (7) a female, died of cancer (organ not specified), aged 55 ; (8) a female, died from convulsions, aged 1 ; (9) the patient himself. From this list it will be seen that of his brothers and sisters two are known to have had cystic kidneys, one died of kidney trouble, one of cancer, and four died under the age of 2 from convulsions. It is possible that the latter four may have suffered from it is possia.

Discussion.

Teuscher ${ }^{1}$ has suggested that crstic formation in the kidneys and the liver depends on an anomaly in the germ plasm. In examining the liver she always found openings between the cysts and the bile passages, and concluded, therefore, that cyst formation was due not to failure of bile ducts to establish their connexion with the larger bile passages, but to a capacity for growth on the part of the epithelium. She suggested that the cystic development was an expression of a perverted tendency, widespread in the body, for tissues of the excretory ducts to multiply at the expense of the more highly differentiated glandular tissue. The above family history appears to confirm her theory that a predisposition to the disease is hereditary, since two of its members were known to have suffered from cystic disease, and five others may have done so.

I am indebted to Dr. Rupert Waterhouse for permission to publish this case.

Tenscher: Ueber die kongenitale Cystenleber mit Cystennieren und Cystenpankreas, Licit. z. path. Anat. u. z. all!g. P'ath., Jena, 1926, 1xxr,
$459-485$.

\section{fttemtoranta: \\ MEDICAL, SURGICAL, OBSTETRICAL.}

\section{SIMPLE MASTOIDITIS WITH SYMPTOMS OF CEREBRAL ABSCESS.}

The following case, which recently came under my care, is of interest because at the time of operation I was quite prepared to find a temporo-sphenoidal abscess, the symptoms and general appearance of the patient pointing to this condition.

A married woman, aged 58, first consulted me about six months ago; she was suffering from acute suppurative otitis media of the left ear. On examination the membrana tympani was found in the postero-superior quadrant, through which thick pus was oozing. There was a certain amount of mastoid tenderness, and gencral malaise with a slight rise of temperature. Under treatinent the condition improved, the tenderness disappeared, and the discharge, which was profuse at first, later became less.

After the eighth week an exacerbation occurred, and, the perforation already present being inadequats, a fresh incision was made in the drum, thereby increasing the size of the existing opening. This only partly relieved the pain and tenderness, and a second operation was performed twelve days later to allow free cxit to the discharge, which was very thick and plentiful.

The general condition became worse, and when I saw her fourteen days later she presented the following picture. She looked extremely ill and wasted, with a rather terrified expression. She complained of deep-seated pain in the left temporal fossa, and tenderness over the squamo-parietal bone. Sleep had been impossible for several days owing to the intense pain; sickness and retching were complained of. The temperature was subnormal, being $97.6^{\circ} \mathrm{F}$., and the pulse was 70 ; the aural discharge normal, being $97.6^{\circ} \mathrm{F}$, and the pulse was 70 ; the aural discharge
had ceased. There was no oedema or tenderness on pressure over the mastoid region, but slight pain was experienced on deep pressure beneath the tip of the mastoid and upper part of the jugular vein.

The symptoms were those of a temporo-sphenoidal abscess, and, as the patient was obviously very ill indeed, could not endure the pain much longer, and was becoming unbalanced mentally, I decided to operate without delay. I made the ustal post-aura incision, and exposed the entire mastoid region; the bone looked incision, and exposed the entire mastoid region; the bone looked quarter of an inch I struck a large quantity of pus coming from the middle ear and antrum, and also from the deep surface of the mastoi! tip. Having cleared out the cells, which were numerous and extended well up on the squamous plate of the temporal bone and into the zygoma, I found the tegmen quite healthy. Not being satisfied, I removed it, and exposed the dura of the middle fossa, which was also healthy. On these findings, and as the symptoms present did not justify me in doing so, I decided not to open the dura mater. The deep surface of the mastoid process was entirely eaten away, and the lower end of the lateral sinus exposed and covered with granulations. Just towards the end of the operation I must have slightly damaged the sinus, as profuse haemorrhage occurred, which could only be stopped by plugging the lower part of the cavity. This was left in situ, and having plugged the rest of the operation cavity with gauze soaked in iodoform emulsion, the skin incision was closed with the exception of the lower end, which was kept open for drainage and lavage. The patient made an uninterrupted recovery.
and

This case is interesting because it shows: (1) the presence of extensive mastoid disease with what one might almost call an absence of symptoms of mastoiditis; (2) the presence of symptoms of cerebral abscess in the absence of any intracranial complication.

Herbert V. O'Shea, M.D., M.Ch., D.L.O.

London, w.1.

INGUINAI HERNIA IN A MONORCHID.

Is view of the interesting questions raised by the occurrence of a right-sided oblique inguinal hernia in the absence of a descended right testicle, the following clinical cletails of such a case seem to be worth recording.

A Hindu male labourer, aged 31, was admitted into the Ranbir Hospital, Jind, May 22nd, with a reducible swelling in the upper part of the right side of the scrotim of over ten years' duration. The swelling had been small at first, but it eventually reached the size of a big plum, descending very frequently and on the slightest exertion; when down it was not easily reducible, and the patient could no longer undertake any hard work. He attributed the condition to an attack of influenza in the pandemic buted the condition to an attack of influenza in the pandemic
of 1918. On examination of the upper part of the right side of the scrotum in which there was no testicle a soft swelling as large as a big plum was found; there was pulsation on coughing but no testicular sensation. It could be reduced and the opening behind it could admit two finger tips. On deep palpation in the region of the internal abdominal ring, no swelling could be made out. There was no history of there having been a right testicle in the scrotum nor of any operation on that side; no scar was found; the left testicle was operation on that side; no scar was found; the left testicle was
apparently normal. The patient had married about twelve years apparently normal. The patient had married about twelve years previously and was the father of five children, of whom four
had died, the survivor being 8 years old. Virility was said to be unimpaired, and no other member of the family is monorchid. The patient was of a sturdy appearance and had a strong abdominal wall.

On May 23rd the usual incision for inguinal hernia was made; the aponcurosis of the external oblique was incised in the direction of its fibres and the sac was identified underneath it; it was separated but no cord could be made out. A small opening was separated but no cord could be made out. A small opening was sac was easily replaced into the peritoneal cavity, traced towards the inner side, and found to be firmly adherent to the pubic spine. Efforts were made to separate it from its attachment, but this was found difficult, so it was cut across as near the bone as possible; the neck was tied, and the distal portion removed, the stump being transfixed in the usual way. The inferior It was artery was seen pulsating on the inner side of the sac. the external oblique were not quite uniformly thick, otherwise they the external oblique were not quite uniformly thick, otherwise they
were strong and the abdominal wall was quite firm. The wound were strong and the abdominal wall was quite firm. The wound was closed in the usual way; the patient made an uneventful
recovery and was discharged cured on June 11th. One month later, and again after two months, he remained perfectly well and was anxious to resume his occupation; he had started carrying some heavy loads, though advised to abstain from such work for six months.

An interesting point is that the case is one of right-sided oblique inguinal hernia in a monorchid. It appears that the gubernaculum developed normally and followed the usual dircetion, as did the peritoneal sac, so it was not clear why the testicle lagged behind. Was this due to the absence of some substance in the gubernaculum which failed to attract the testicle down, or was the testicle totally absent on that side? A second question is why it took so long for the peritoneal contents to make their way into the sac; perhaps it had become sealed, though iniperfectly, and, later, when the patient was debilitated by influenza in 1918, the great omentum succeeded in working its way through the internal abdominal ring. Thirdly, if the sac was attached to the pubic spine, how did the swelling appear in the upper part of the scrotum? It appears that the contents of the sac while making their way towards the fundus. encountered the resistance of the bone, and took the path of least resistance-the external abdominal ring-making a loop in the lower part of the sac. This case evidently supports the congenital theory for inguinal hernia suggested by Hamilton Russell. I should be glad to know whether other similar cases have been recorded.

Jind City.

Hari D̈iss, M.B., F.R.C.S.E. 